\title{
To the statistic theory of dispersion of tensors of electric conductivity and dielectric susceptibility of electrolyte solutions
}

\author{
S.Odinaev ${ }^{1}$, I.Ojimamadov ${ }^{2}$ \\ 1 Physics-Technical Institute, Academy of Sciences, \\ Republic of Tajikistan, 299/1 Aini Ave, Dushanbe, 734063 \\ 2 M.S.Osimi Tajik Technical University, \\ Akad. Rajabovs Str., 10, Dushanbe 734042, Republic of Tajikistan
}

Received April 28, 2004

\begin{abstract}
We have obtained an equation describing space-time behaviour of the current density component by using kinetic equation for one-particle distribution function for the structural units of the solution with the generalized Vlasov potential.

The analytic expression for the complex tensor of electroconductivity $\sigma(\omega)$ is given derived from the Fourier-transform and from the comparison with the differential form of the Ohm's law. This permitted us to obtain the dielectric susceptibility tensor $\varepsilon(\omega)$ for conducting media.

By identifying the longitudal $\varepsilon_{\|}$and transversal $\varepsilon_{\perp}$ parts one can determine the anisotropy of the dielectric susceptibility for electrolyte solutions.
\end{abstract}

Key words: kinetic equation, distribution functions, frequency dispersion, dielectric susceptibility tensor, electric conductivity tensor

PACS: $61.20 . \mathrm{Qg}, 51.10 .+y$

\section{Introduction}

Rather high accuracy and easiness of measurement of electroconductivity has long attracted the efforts of numerous researchers who have gathered enormous experimental material. However theoretical research of electroconductivity of electrolyte solutions is one of the most complicated and difficult questions of physics of liquid state. Research of irreversible processes in electrolyte solutions, in particular of electroconductivity, belongs to Onsager. Generalization on the cases of conductivity of an alternating current was carried out by Debye and Falkenhagen. Further

*E-mail: ods@ttu.tajik.net 
development of the theory of electroconductivity, based on the use of nonequilibrium multiparticle distribution functions, is presented in works [1-3]. Undoubtedly, the possibility to determine dynamic coefficients of electroconductivity and dielectric susceptibility is of great interest. Thus, the purpose of the present work is to determine these parameters as well as the appropriate modules of elasticity in view of anisotropy depending on constituents, structure of solution and thermodynamic parameters based on the molecular-kinetic theory.

First of all we accept the kinetic equation for one-particle distribution function $f_{a}\left(\vec{\chi}_{a}, t\right)$ of $a$ type structural units of electrolyte solutions with generalized Vlasov potential [4]:

$$
\frac{\partial f_{a}}{\partial t}+\frac{p_{a}^{\alpha}}{m_{a}} \cdot \frac{\partial f_{a}}{\partial q_{1}^{\alpha}}+e_{a} E^{\alpha}\left(\vec{q}_{1}, t\right) \frac{\partial f_{a}}{\partial p_{a}^{\alpha}}+F_{a}^{\alpha}\left(\vec{q}_{1}, t\right) \frac{\partial f_{a}^{0}}{\partial p_{a}^{\alpha}}=I_{\mathrm{c}}\left(f_{a}\right),
$$

where

$$
\begin{aligned}
& F_{a}^{\alpha}\left(\vec{q}_{1}, t\right)=\sum_{b} \int\left\{F_{a b}^{\alpha}(l) \delta(t-\tau)-\Omega \mathrm{e}^{-\Omega(t-\tau)}\left(F_{a b}^{\alpha}(l)-F_{a b}^{\alpha}(c)\right)\right. \\
& \left.+\mathrm{e}^{-\Omega(t-\tau)} F_{a b}^{\alpha}(e l)\right\} \mathrm{d} \tau \\
& I_{\mathrm{c}}\left(f_{a}\right)=\beta_{a} \frac{\partial}{\partial \bar{p}_{a}^{\alpha}}\left[\frac{\tilde{p}_{a}^{\alpha}}{m_{a}} f_{a}+k T\left(\vec{q}_{1}, t\right) \cdot \frac{\partial f_{a}}{\partial p_{a}^{\alpha}}\right] \\
& F_{a b}^{\alpha}(\ell)=n_{b} \int \frac{\partial^{2} \Phi_{a b}}{\partial r^{2}} \cdot \frac{r^{\alpha} r^{\beta}}{r^{2}} g_{a b}^{o}(r)\left(U^{\beta}\left(\vec{q}_{2}, t\right)-U^{\beta}\left(\vec{q}_{1}, t\right)\right) \mathrm{d} \vec{r} \\
& F_{a b}^{\alpha}(c)=n_{b} \int \frac{\partial^{2} K_{a b}}{\partial r^{2}} \cdot \frac{r^{\alpha} r^{\beta}}{r^{2}}\left(U^{\beta}\left(\vec{q}_{2}, t\right)-U^{\beta}\left(\vec{q}_{1}, t\right)\right) \mathrm{d} \vec{r}, \\
& F_{a b}^{\alpha}(e \ell)=n_{b}\left(\frac{e_{b}}{\beta_{b}}-\frac{e_{a}}{\beta_{a}}\right) \cdot \int \frac{\partial^{2} \Phi_{a b}}{\partial r^{2}} \cdot \frac{r^{\alpha} r^{\beta}}{r^{2}} g_{a b}^{o}(r) \mathrm{d} \vec{r} \cdot E^{\beta}\left(\vec{q}_{1}, t\right), \\
& K_{a b}^{\alpha}(r)=\int_{-\infty}^{\left|\overrightarrow{q_{2}}-\vec{q}_{1}\right|} \frac{\partial \Phi_{a b}(y)}{\partial y} \cdot Z_{a b}(y) \mathrm{d} y, \quad \vec{r}=\vec{q}_{2}-\vec{q}_{1}, \\
& Z_{a b}(y)=\left[n_{o}\left(\frac{\partial g_{a b}^{o}(r)}{\partial n_{o}}\right)_{T}+\gamma T_{o}\left(\frac{\partial g_{a b}^{o}(r)}{\partial T_{o}}\right)_{n}\right], \\
& \gamma=\frac{1}{n_{o} C_{v}}\left(\frac{\partial P_{o}}{\partial T_{o}}\right)_{n_{o}}, \quad \vec{x}_{a}=\left(\rightrightarrows q_{a}, \vec{p}_{a}\right),
\end{aligned}
$$

$f_{a}^{o}\left(p_{a}\right)=n_{a}\left(2 \pi m k T_{0}\right)^{-3 / 2} \exp \left(-p_{a}^{2} / 2 m_{a} k T_{0}\right)-$ is equilibrium Maxwell distribution function; $m_{a}, \vec{q}_{a}, \vec{p}_{a}$ - are mass, coordinate and momentum of particles of $a$ type, respectively, $\tilde{p}_{a}^{\alpha}=p_{a}^{\alpha}-m_{a} v^{\alpha}\left(\vec{q}_{1}, t\right)$ - is relative momentum, $e_{a}=z_{a} e, e_{b}=z_{b} e, e-$ is an elementary charge; $z_{a}, z_{b}, \beta_{a}, \beta_{b}$-are valency and friction coefficients of particles of $a$ and $b$ types, respectively, $E^{\alpha}\left(\vec{q}_{1}, t\right)$ - are the components of electric field, $\Phi_{a b}(|\vec{r}|)$ - is the potential energy of interaction between the structural units of solution, and 
$g_{a b}^{0}(r)$ - is radial distribution function, describing equilibrium structure of solution, which according to [5], we consider as known, $\vec{U}_{a}(\vec{q}, t)-$ is displacement vector of particles of $a$ type, $\Omega=\Omega_{a b}=\tau_{a b}^{-1}=\left(k T / d_{a b}^{2}\right) \cdot\left(1 / \beta_{a}+1 / \beta_{b}\right)$ is phenomenological frequency of structural relaxation, $k$ is Boltzman's constant, $d_{a b}=1 / 2\left(d_{a}+d_{b}\right), d_{a}$, $d_{b}$ - are diameters of structural units of solutions of $a$ and $b$ types. Right-hand side of the equation (1), i.e. $I_{\mathrm{c}}\left(f_{a}\right)$ is the collision Fokker-Plank term, which is derived in the approximation of pair interactions. It provides irreversibility of the initial equation in time, i.e. the possibility to describe the dissipation processes in solutions. For convenience, let us put the coordinates of particles $\vec{q}_{a}=\vec{q}_{1}, \vec{q}_{b}=\vec{q}_{2}, \vec{q}_{\mathrm{c}}=\vec{q}_{3}$ and so on. It should be mentioned that particles of the solution interact by the potential $\Phi_{a b}\left(|\vec{r}|, \Omega_{\mathrm{s}}\right)$, which consists of the sum of the energy of inter-ionic (kations and anions) $\Phi_{i j}$, ion-molecular $\Phi_{i s}$ and $\Phi_{j s}$, and intermolecular $\Phi_{s s}$ interactions. Here $\Omega_{\mathrm{s}}=\left(v_{\mathrm{s}}, \alpha_{\mathrm{s}}\right)$ - are polar angles describing the orientation of the dipole around the axis, connecting mass centers of interacting particles.

Let us use the definitions of pulse moments of the function $f_{a}\left(\vec{x}_{a}, t\right)$ according to [6] and introduce the vector of density of current $\vec{j}(\vec{q}, t)$ :

$$
\begin{aligned}
\rho_{a}\left(\vec{q}_{1}, t\right) & =e_{a} n_{a}\left(\vec{q}_{1}, t\right)=e_{a} \int f_{a}\left(\vec{x}_{a}, t\right) \mathrm{d} \vec{p}_{a}, \\
\rho_{a} v_{a}^{\alpha}\left(\vec{q}_{1}, t\right) & =e_{a} \int \frac{p_{a}^{\alpha}}{m_{a}} f_{a}\left(\vec{x}_{a}, t\right) \mathrm{d} \vec{p}_{a}, \\
K_{a a}^{\alpha \beta}\left(\vec{q}_{1}, t\right) & =\int \frac{\tilde{p}_{a}^{\alpha} \tilde{p}_{a}^{\beta}}{m_{a}} f_{a}\left(\vec{x}_{a}, t\right) \mathrm{d} \vec{p}_{a}, \\
\vec{j}\left(\vec{q}_{1}, t\right) & =\sum_{a} \vec{j}_{a}\left(\vec{q}_{1}, t\right)=\sum_{a} \rho_{a}\left(\vec{v}_{a}-\vec{v}\left(\vec{q}_{1}, t\right)\right),
\end{aligned}
$$

as well as conditions of electroneutrality

$$
\sum_{a} e_{a} n_{a}=e \sum_{a} z_{a} n_{a}=0
$$

where $\rho_{a}, v_{a}^{\alpha}, K_{a a}^{\alpha \beta}-$ are volumetric density of charge, components of average speed and kinetic part of the tensor of flow of momentum of particles of $a$ type, respectively.

Using the method of pulse moments of one-particle distribution function $f_{a}\left(\vec{x}_{a}, t\right)$ , multiplying equation (1) by $\left(e_{a} p_{a}^{\alpha}\right) / m_{a}$ and integrating by $\mathrm{d} \vec{p}_{a}$, taking into account equations (2)-(4), we derive for the components of the vector of density of current $j_{a}^{\alpha}\left(\vec{q}_{1}, t\right)$, the following equation:

$$
\frac{\partial j_{a}^{\alpha}\left(\vec{q}_{1}, t\right)}{\partial t}+\nu_{a} j_{a}^{\alpha}=\frac{n_{a}^{0} e_{a}^{2}}{m_{a}}\left[E^{\alpha}\left(\vec{q}_{1}, t\right)-\sum_{b} \frac{1}{e_{a}} \int \vec{e}^{\Omega(t-\tau)} F_{a b}^{\alpha}(e l) \mathrm{d} \tau\right]
$$

where

$$
\nu_{a}=\tau_{a}^{-1}=\beta_{a} / m_{a} .
$$


Performing Fourier-transformation by time in (5) and solving it in regard to $j_{a}^{\alpha}(\omega, \vec{q})$, for the components of the vector of density of current $j^{\alpha}(\omega)=\sum_{a} j_{a}^{\alpha}\left(\omega, \vec{q}_{1}\right)$, we receive

$$
j^{\alpha}(\omega)=\sum_{a} \frac{n_{a}^{0} e_{a}^{2} / \beta_{a}}{1-\mathrm{i} \omega \tau_{a}}\left[\delta^{\alpha \beta}+\sum_{b} \frac{\tau_{\mathrm{c}} G_{e l}^{\alpha \beta}(0) / e_{a}}{1-\mathrm{i} \omega \tau_{\mathrm{c}}}\right] E^{\beta}(\omega)
$$

where

$$
G_{e l}^{\alpha \beta}(0)=n_{b}^{0}\left(\frac{e_{b}}{\beta_{b}}-\frac{e_{a}}{\beta_{a}}\right) d_{a b} \int \frac{\partial^{2} \Phi_{a b}}{\partial r^{2}} \cdot \frac{r^{2} r^{\beta}}{r^{2}} g_{a b}^{0}(r) \mathrm{d} \vec{r} .
$$

Comparing (6) with the Fourier-image of the differential form of Ohm law, for complex tensor of electroconductivity $\tilde{\sigma}^{\alpha \beta}(\omega)$ we have:

$$
\tilde{\sigma}^{\alpha \beta}(\omega)=\sum_{a} \frac{n_{a}^{b} e_{a}^{2} / \beta_{a}}{1-i \omega \tau_{a}}\left[\delta^{\alpha \beta}+\sum_{b} \frac{\tau_{\mathrm{c}} \cdot G_{e l}^{\alpha \beta}(0)}{e_{a}\left(1-i \omega \tau_{\mathrm{c}}\right)}\right] .
$$

As to each process of transition in hydrodynamic mode, the certain elastic properties in a high-frequency mode will correspond. Further, according to [6] we shall introduce the complex tensor of electroelasticity module:

$$
\tilde{\epsilon}^{\alpha \beta}(\omega)=-\mathrm{i} \omega \tilde{\sigma}^{\alpha \beta}(\omega)=\epsilon^{\alpha \beta}(\omega)-\mathrm{i} \omega \sigma^{\alpha \beta}(\omega),
$$

where the real part $\in^{\alpha \beta}(\omega)$ - is the dynamic tensor of electroelasticity module, and imaginary part $\sigma^{\alpha \beta}(\omega)$ - is the dynamic tensor of electroconductivity.

Substituting (8) into (9), and dividing real and imaginary parts for $\in^{\alpha \beta}(\omega)$ and $\sigma^{\alpha \beta}(\omega)$, we receive:

$$
\begin{aligned}
& \epsilon^{\alpha \beta}(\omega)=\sum_{a} \in_{a}^{0}\left[\left(\omega \hat{\tau}_{a}\right)^{2} \delta^{\alpha \beta}+\omega^{2} \hat{\tau}_{a} \hat{\tau}_{\mathrm{c}}\left(\tau_{a}+\tau_{\mathrm{c}}\right) \sum_{b} \frac{G_{e l}^{\alpha \beta}}{e_{a}}\right], \\
& \sigma^{\alpha \beta}(\omega)=\sum_{a} \in_{a}^{0}\left[\hat{\tau}_{a} \delta^{\alpha \beta}+\hat{\tau}_{a} \hat{\tau}_{\mathrm{c}}\left(1-\omega^{2} \tau_{a} \tau_{\mathrm{c}}\right) \sum_{b} \frac{G_{e l}^{\alpha \beta}}{e_{a}}\right],
\end{aligned}
$$

where

$$
\hat{\tau}_{a}=\frac{\tau_{a}}{1+\left(\omega \tau_{a}\right)^{2}}, \quad \hat{\tau}_{\mathrm{c}}=\frac{\tau_{\mathrm{c}}}{1+\left(\omega \tau_{\mathrm{c}}\right)^{2}},
$$

$\in_{a}^{0}=n_{a}^{0} e^{2} / m_{a}, \tau$ and $\tau_{\mathrm{c}}$ is time of translational and structural relaxation, respectively.

The expressions in system (10) describe the frequency dispersion of electroelastic modules and coefficients of electroconductivity in a wide interval of variations of thermodynamic parameters and frequencies of external action. In these expressions the frequency dependence is caused by contributions of both translational and structural relaxation. Potential parts of these coefficients contain the integral terms which are defined by means of energy of interaction of structural units of the solution $\Phi_{a b}(r)$ and equilibrium radial distribution function $g_{a b}^{0}(r)$. At a certain choice of the model of solution, according to [5], the latter could be considered as known. Debye 
and Falkengagen [7], being restricted by the real part of electroconductivity, investigated frequency dispersion electroconductivity of electrolyte solutions. The second equation of the system (10) is the generalization of the effect of Debye-Falkenhagen for electrolyte solutions, the frequency behaviour of which coincides with the results of general relaxation theories. Formulas of the system (10) make it possible to investigate the asymptotic behaviour of these expressions both in hydrodynamic and in high-frequency mode and correspond to the general conclusions of the statistical theory of electroelastic properties of solutions.

At low frequencies (hydrodynamic mode $\omega \rightarrow 0$ ) expressions (10) describe electroconductivity properties of solutions, and at fast processes (high-frequency mode $\omega \rightarrow \infty)$ - only the elastic properties could be described.

Expressions (10) also permit to investigate dispersion of dielectric susceptibility of solutions. Following paper [8], it is also possible to determine a frequency dispersion of tensor of dielectric susceptibility $\tilde{\varepsilon}^{\alpha \beta}(\omega)$ for conducting media, which is connected to conductivity tensor $\tilde{\sigma}^{\alpha \beta}(\omega)$ by the ratio

$$
\tilde{\varepsilon}^{\alpha \beta}(\omega)=\delta^{\alpha \beta}+\frac{\mathrm{i}}{\varepsilon_{0} \omega} \tilde{\sigma}^{\alpha \beta}(\omega) .
$$

The latter enables one to determine longitudinal $\sigma_{\|}, \varepsilon_{\|}$and transversal $\sigma_{\perp}, \varepsilon_{\perp}$ components of these coefficients, as well as based on the Maxwell equations, to determine the longitudinal $\vec{E}_{\|}(\omega, \vec{k})$ and transversal $\vec{E}_{\perp}(\omega, \vec{k})$ parts of the vector of electric field $\vec{E}(\omega, \vec{k})$ with regard to its wave vector $\vec{k}$ in electrolyte solutions, which is the purpose of the further research.

\section{References}

1. Ebeling W., Feistel R., Kelbg G., Sanding R. Generalizations of Onsagers semi phenomenological theory of electrolytic conductance. // J. non-equilibr. thermodlyn., 1978, vol. 3, No. 1, p. 11-28.

2. Sänding R. Theory of linear vectors transport processes in binary isothermal electrolyte solutions. // Z. Phys. Chem. (DDR), 1984, vol. 265, No. 4, p. 663-680.

3. Lessner G. The electric conductivity of stationary and homogenous electrolytes up to concentration $C=1 \mathrm{~mol} / \mathrm{L}$ and high electric fields. // Physica A, 1982, vol. 116, No. 1-2, p. 272-288; Physica A, 1983, vol. 122, No. 3, p. 441-458.

4. Odinaev S., Ojimamadov I. About one kinetic equation with generalized Vlasov's potential. - In: Int. conf. PLMMP, abstracts. Kyiv, September 14-19, 2001, p. 35.

5. Yukhnovsky I.R., Holovko M.F. Statistic Theory of Classical Equilibrium Systems. Kiyv, Naukova Dumka, 1980, p. 372, (in Russian).

6. Odinaev S., Adkhamov A.A. Molecular Theory of Structural Relaxation and Transition Phenomena in Liquids. Dushanbe, Donish, 1998, p. 230, (in Russian).

7. New issues of contemporary electrochemistry, (ed. J.M.Bokris). Moscow, Inostrannaya literature, 1962, p. 462, (in Russian).

8. Klimontovich Yu.Ya. Statistic Theory of Non-Equilibrium Phenomena in Plasmas. Moscow, Moscow State University Publisher, 1964, p. 281, (in Russian). 


\section{До статистичної теорії дисперсії тензорів електропровідності і діелектричної сприйнятливості розчинів електролітів}

\section{С.Одінаєв ${ }^{1}$, І.Оджімамадов ${ }^{2}$}

1 Фізико-технічний інститут, Академія наук, Душанбе, Республіка Таджикистан

2 Таджицький технічний університет ім. М.С.Осімі, Душанбе, Республіка Таджикистан

Отримано 28 квітня 2004 р.

Отримано рівняння, яке описує просторово-часову поведінку компоненти густини струму, використовуючи кінетичне рівняння для одночастинкової функції розподілу структурних компонент розчину з узагальненим потенціалом Власова.

Представлено аналітичний вираз для комплексного тензора електропровідності $\sigma(\omega)$, який виведений з Фур'є-перетворення і 3 диференціальної форми закону Ома. Це дало змогу отримати тензор діелектричної сприйнятливості $\varepsilon(\omega)$ для провідного середовища. Виділяючи поздовжню $\varepsilon_{\|}$i поперечну $\varepsilon_{\perp}$ частини можна визначити анізотропію діелектричної сприйнятливості для електричних розчинів.

Ключові слова: кінетичне рівняння, функції розподілу, частотна дисперсія, тензор діелектричної сприйнятливості, тензор електропровідності

PACS: $61.20 . \mathrm{Qg}, 51.10 .+y$ 